Artigo

\title{
Comparação de metodologia utilizada para a detecção de Hemoglobina S (Hb S) em doadores de sangue
}

\author{
Brígida C. A. B. Prudêncio ${ }^{1}$ \\ Dimas T. Covas \\ Claudia R. Bonini-Domingos ${ }^{3}$
}

\begin{abstract}
O Brasil apresenta alta prevalência dehemoglobina S, com nítidas diferenças regionaismarcadas pelos processos demiscigenação da população. A presen ça desta hemoglobina tem sido objeto deestudo, não só em pacien tes com anemia falciforme (homozigotos para hemoglobina S - Hb SS), mas também em portadores desta variante de hemoglobina em heterozigose (Hb AS). As complicações clínicas dos portadores são influenciadas por fatores genéticos e ambientais. De acordo com a portaria 1376 de 19 de novembro de 1993 para Normas técnicas de coleta, processamento e transfusão de sangue, componentes e derivados, do Ministério da Saúde, deve ser realizada a detecção de hemoglobinas an ormais em doadores de sangue. Diante desta normatização eàstaxas dehemoglobina $\mathrm{S}$ em nossa população, objetivamos no presen te trabalho a identificação da hemoglobina S, utilizando técnicas de triagem utilizadas na rotina de Bancos de Sangue, como o kit de identificação para hemoglobina $S$ da Diamed, comercializado pela designação ID-Hb S, e o teste de solubilidade. Os casos que apresentaram positividadenesta triagem foram posteriormenteconfirmados em eletroforese em pH alcalino e ácido. Do total de 5.416 doadores de sangue analisados pelo teste de triagem (ID - Hb S Diamed e solubilidade), 50 (0,92\%) apresentaram hemoglobina S. Após confirmação eletroforética evidenciamos a compatibilidade das técnicas em $100 \%$ dos casos analisados. 0 teste da Diamed apresenta custo de $R \$ 1,20$ por doador e o de solubilidade $R \$ 0,14$. Pelos resultados obtidos sugerimos o uso do teste de solubilidade como de escol ha, para triagem de hemoglobina $\mathrm{S}$ em bancos de sangue, não só pela eficácia e praticidade, como também pelo baixo custo.

Rev.bras.hematol.hemoter., 2000, 22(2): 99-109
\end{abstract}

Palavras-chave: doadores de sangue, diagnóstico laboratorial, hemoglobina S, triagem

\section{Introdução}

A síntese da cadeia de globina é um processo complexo e, embora muito seguro, podem ocorrer erros, o que leva ao aparecimento de variações na estrutura da hemoglobina (1, 2). Os efeitos fisiopatológicos são variáveis na dependência do defeito e do local $(3,4,5,6)$. Cerca de 700 hemoglobinas variantes são conhecidas, sendo as mais freqüentes a $\mathrm{Hb} \mathrm{S}, \mathrm{Hb} \mathrm{C}$ e a $\mathrm{Hb}$ D Punjab. Quando o controle genético falha (substituição

1 - Médica, Mestre em Ciências da Saúde, Hemonúcleo de Fernandópolis, Hemocentro de Ribeirão Preto, SP

2 - Professor Doutor, Diretor do Hemocentro de Ribeirão Preto, SP

3 - Professora Doutora, Curso de Pós-graduação em Ciências da Saú de, FAMERP, Faculdade de Medicina de São José do Rio Preto, SP

Trabalho realizado no Hemocentro de Ribeirão Preto e Hemonúcleo de Fernandópolis, SP

Correspondência para: Brígida Cristina do Amaral Botelho Prudêncio

Rua Rio de Janeiro, 553. CEP 15600-000. Fernandópolis. SP

Fone (17) 442-5544. Fax: (17) 442-5447 
ou mudança da seqüência), surgem as chamadas hemoglobinas variantes. $(7,8,9,10$, 11). As prevalências de $\mathrm{Hb} \mathrm{S}$ são altamente variáveis no país, dependendo da região estudada e enfoques específicos devem ser colocados em cada caso $(13,14,15,16,17)$. As prevalências encontradas em doadores de sangue obedecem aos valores observados na população geral e evidenciam a necessidade de programas preventivos para esta alteração de hemoglobina $(9,17,18)$.

Baseados em diversas técnicas, tem sido motivo de estudo no Brasil a detecção de Hb S em doadores de sangue, segundo portaria $\mathrm{n}$ 1376 de 19 de novembro de 1993 (12). A importância de avaliações destas hemoglobinas reside na necessidade da melhoria, a cada dia, da qualidade do sangue a ser transfundido, além do aspecto educacional, cujos portadores deverão ser orientados sobre sua alteração genética e aconselhados a realizar exames em seus familiares.

Devido à necessidade de adaptarmos às normas da hemoterapia, às necessidades solicitadas pelo governo, o presente trabalho objetivou a padronização de técnica de triagem de hemoglobina $\mathrm{S}$ em doadores de sangue, através da comparação dos testes de triagem de hemoglobina S (ID Diamed) em doadores, em uso em bancos de sangue, com teste de solubilidade ajustado para esta finalidade.

\section{Material e Métodos}

No período de novembro de 1997 a maio de 1998, foram estudados, para verificar a presença $\mathrm{Hb} \mathrm{S}$, todos os doadores de sangue aptos que se apresentaram ao Núcleo de Hemoterapia de Fernandópolis, provenientes de coleta externa e interna, totalizando 5.146 indivíduos. As coletas externas foram realizadas dentro da região administrativa no eixo Fernandópolis, Jales e Santa Fé do Sul. Incluemse aqui as coletas externas na região administrativa de Araçatuba, dada a abrangência gerencial do Hemocentro de Ribeirão Preto, ao qual estamos ligados. No que se refere à coleta interna, foram utilizados os doadores aptos que se apresentaram no Hemonúcleo, provenientes, na sua maioria, da cidade de Fernandópolis.
As amostras de sangue foram colhidas por punção venosa, durante o processo de doação, em tubos com anticoagulante, após autorização dos doadores para utilização dos dados em pesquisa, conforme orientação do Comitê de Ética em Pesquisa.

Todas as amostras foram submetidas sequencialmente aos seguintes testes de triagem e confirmação de hemoglobina S: Cartão em gel ID-Hb S Diamed; Testes de solubilidade (7); Eletroforese em pH alcalino (19); Eletroforese em pH ácido (20). Para as eletroforeses foram utilizados os géis de agarose da CELM - Compahia Equipadora de Laboratórios Modernos, por apresentarem boa resolução das frações.

0 teste de solubilidade aplicado foi fundamentado na insolubilidade da $\mathrm{Hb} \mathrm{S}$, quando no estado reduzido. As hemoglobinas normais e as variantes comuns, como, por exemplo, C, D, N, I são solúveis nestas condições. É um teste que serve apenas para detectar a presença de $\mathrm{Hb} \mathrm{S}$ (7).

\section{Reagentes:}

Solução Fosfato:

- KH2PO 4 (anidro) ................. 33,78 g

- K2HPO 4 (anidro) ................. 59,33 g

- saponina P.A.

- água destilada $250 \mathrm{ml}$

\section{Ditionito de sódio}

\section{Procedimento:}

Dissolver $100 \mathrm{mg}$ de ditionito de sódio em $10 \mathrm{ml}$ da solução fosfato. Esta quantidade é suficiente para 5 testes.

- Em um tubo contendo $2 \mathrm{ml}$ da solução acima preparada, adicionar 20 microlitros de san

- Misturar por rotação e aguardar 2 minutos

- Colocar o tubo a $2 \mathrm{~cm}$ de um papel branco traçado com linhas negras horizontais

\section{Interpretação:}

- A turvação da solução (insolubilidade) indica presença de $\mathrm{Hb}$ S; não se observam as linhas negras

- As hemoglobinas solúveis permitem a observação das linhas traçadas no papel 


\section{Precauções:}

- Os sais de fosfato (KH2PO4 e K2HPO4) devem ser anidro

- É aconselhável o uso de amostra normal como controle. O controle, inclusive, pode sofrer ligeira reação floculante, porém as linhas negras são sempre visíveis

- Para amostras de sangue com hematócrito abaixo de $20 \%$, há necessidade de usar 50 microlitros de sangue

\section{Resultados}

Do total de 5.416 doadores analisados, $3.621(66,85 \%)$ foram do sexo masculino e $1.795(33,15 \%)$ do sexo feminino; $4.573(84,43$ $\%)$ eram brancos, 705 (13,01\%) mulatos e $138(2,54 \%)$ negros. 50 doadores (0,92 \%) apresentaram positividade nos testes de triagem para $\mathrm{Hb} \mathrm{S}$ realizados através de IDSickle cell - Diamed e teste de solubilidade, sendo posteriormente confirmados por eletroforese em $\mathrm{pH}$ alcalino e ácido. Destes $25(0,46 \%)$ eram masculinos e 25 doadores $(0,46 \%)$ femininos. Com relação à cor da pele, 22 doadores $(0,40 \%)$ eram brancos , 20 doadores $(0,36 \%)$ mulatos e oito doadores $(0,14 \%)$ negros.

Não observamos positividade nos testes de triagem para Hb S em 5.366 (99,07 \%) doadores, dos quais $3.596(67,01 \%)$ eram do sexo masculino, $1.770(32,98 \%)$ do sexo feminino, 4.551 (84,81\%) brancos, 685 (12,76\%) mulatos e $130(0,24 \%)$ negros, cujos resultados podem ser melhor visualizados na Tabela 1.

Os dados do último senso (1996) da cidade de Fernandópolis, de acordo com o IBGE, mostram que a constituição da população é de: $81,5 \%$ - brancos, $15,2 \%$ - mulatos, 2,08 \% negros, $1,15 \%$ - outras origens. Estes dados foram compatíveis com a população de doadores por nós avaliada.

Do total de 5.416 doadores analisados, 4.001 (73,87 \%) eram provenientes da região de Fernandópolis, sendo que encontramos hemoglobina S em $23(0,57 \%)$ doadores, sendo $9(39,13 \%)$ do sexo masculino e $14(60,86 \%)$ do sexo feminino, 11 (47,8 \%) eram brancos, 9 (39\%) mulatos e 3 ( $13 \%)$ negros. Esses dados podem ser melhor observados na Tabela 2.
Na região de Araçatuba estudamos um total de 1.415 doadores, sendo 977 (69,1\%) do sexo masculino e 438 (30,9\%) do sexo feminino; 1.113 (80\%) eram brancos, 238 (16,8 $\%)$ mulatos e 50 (3,5 \%) negros. Do total de 27 (1,90\%) doadores com Hb S, encontramos 16 (59 \%) do sexo masculino e 11 (40,7\%) do sexo feminino, sendo 10 (37\%) brancos, $12(44,4 \%)$ mulatos e cinco (18,5 \%) negros. $\mathrm{Na}$ região de Araçatuba, observamos 1,9\% de $\mathrm{Hb} \mathrm{S}$, enquanto que em Fernandópolis a freqüência foi de $0,57 \%$. Os dados referentes a Araçatuba encontram-se na Tabela 3.

As análises laboratoriais para detecção de $\mathrm{Hb} \mathrm{S}$ foram realizadas pelos métodos de gel da Diamed e teste de solubilidade, sendo posteriormente confirmados os casos positivos por procedimentos eletroforéticos. A compatibilidade entre as amostras foi de $100 \%$.

Como os testes eram realizados inicialmente pelo método de gel da Diamed, para depois seguirem na conferência dos outros métodos, realizamos análises em um grupo controle, em que foram testados doadores pelos três métodos durante um mês, e encontramos um único doador com $\mathrm{Hb}$ AS que apresentou $100 \%$ de compatibilidade nos testes aplicados. Pela baixa freqüência de $\mathrm{Hb}$ S encontrada, decidimos avaliar um grupo de 213 negros e descendentes, onde provavelmente obteríamos uma maior freqüência dessa hemoglobina. Avaliamos 213 negros e descendentes e obtivemos 18 portadores de $\mathrm{Hb} \mathrm{AS}$, o que significou uma freqüência de $8,54 \%$, com desvio padrão de 1,91 e intervalo de confiança de $95 \%$. Foram também encontrados quatro portadores de $\mathrm{Hb} \mathrm{AC}$, com freqüência de 1,87\%. Esta amostra apresentou compatibilidade de $100 \%$ nas técnicas ID - Hb S, teste de solubilidade e eletroforese de hemoglobina, afastando, assim, os possíveis falsos positivos e negativos que por ventura viessem ocorrer. As figuras 1 e 2 ilustram amostras por nós testadas durante o procedimento de triagem de $\mathrm{Hb}$ S. As confirmações dos casos positivos, realizadas por procedimentos eletroforéticos em $\mathrm{pH}$ alcalino e ácido com géis da CELM, estão ilustradas nas Figuras 3 e 4. 
Tabela 1. Total de doadores analisados no Núcleo de Hemoterapia de Fernandópolis no período de novembro de 1997 a maio de 1998, com e sem Hb S

\begin{tabular}{l|c|c|c|c|c}
\hline \multirow{2}{*}{\begin{tabular}{l} 
Total analisado \\
\cline { 2 - 6 }
\end{tabular}} & \multicolumn{2}{|c|}{ Sexo } & \multicolumn{2}{c}{ Cor da Pele } \\
\hline $.416(100 \%)$ & $3.621(66,85 \%)$ & $1.795(33,14 \%)$ & $4.573(84,43 \%)$ & $705(13,01 \%)$ & $138(2,54 \%)$ \\
\hline $\begin{array}{l}\text { Com Hb S } \\
50(0,92 \%)\end{array}$ & $25(0,46 \%)$ & $25(0,46 \%)$ & $22(0,40 \%)$ & $20(0,36 \%)$ & $8(0,14 \%)$ \\
\hline $\begin{array}{l}\text { Sem Hb S } \\
5.366(99.07 \%)\end{array}$ & $3.596(67,01 \%)$ & $1.770(32,98 \%)$ & $4.551(84,81 \%)$ & $685(12,76 \%)$ & $130(0,24 \%)$ \\
\hline
\end{tabular}

Hb S- Hemoglobina S

Tabela 2.Doadores examinadosno Núcleo deHemoterapia de Fernandópolis, provenientes da Região deFernandópolis, no período de novembro de 1997 a maio de 1998

\begin{tabular}{c|c|c|c|c|c}
\hline \multirow{2}{*}{$\begin{array}{c}\text { № Doadores } \\
\text { analisados }\end{array}$} & \multicolumn{2}{|c|}{ Sexo } & \multicolumn{3}{c}{ Cor da pele } \\
\cline { 2 - 6 } & Masculino & Feminino & Branca & Mulata & Negra \\
\hline 4.000 & 2.644 & 1.357 & 3.440 & 467 & 88 \\
\hline \multirow{2}{*}{$\begin{array}{c}\text { Com } \\
\text { Hb AS }\end{array}$} & $66,08 \%$ & $33,92 \%$ & $85,9 \%$ & $11,6 \%$ & $2,2 \%$ \\
\hline 23 & Masculino & Fexo & & \multicolumn{2}{c}{ Cor da pele } \\
\hline $0,57 \%$ & 9 & 14 & 11 & Mulata & Negra \\
\hline & $39,1 \%$ & $60,9 \%$ & $47,8 \%$ & $39 \%$ & 3 \\
\hline
\end{tabular}

Hb AS - Traço Falciforme

Tabela 3. Doadores examinados no Núcleo de Hemoterapia de Fernandópolis, provenientes da Região deAraçatuba no período de novembro de 1997 a maio de 1998

\begin{tabular}{c|c|c|c|c|c}
\hline \multirow{2}{*}{$\begin{array}{c}\text { № Doadores } \\
\text { analisados }\end{array}$} & \multicolumn{2}{|c|}{ Sexo } & \multicolumn{3}{c}{ Cor da pele } \\
\cline { 2 - 6 } & Masculino & Feminino & Branca & Mulata & Negra \\
\hline 1.415 & 977 & 438 & 1.133 & 238 & 50 \\
& $69,1 \%$ & $30,9 \%$ & $80 \%$ & $16,8 \%$ & $3,5 \%$ \\
\hline \multirow{2}{*}{ Com } & \multicolumn{2}{|c|}{ Sexo } & \multicolumn{3}{c}{ Cor da pele } \\
\cline { 2 - 6 } Hb AS & Masculino & Feminino & Branca & Mulata & Negra \\
\hline 27 & 16 & 11 & 10 & 12 & 5 \\
$1,90 \%$ & $59 \%$ & $40,7 \%$ & $37 \%$ & $44,4 \%$ & $18,5 \%$ \\
\hline
\end{tabular}

Hb AS - Traço Falciforme 


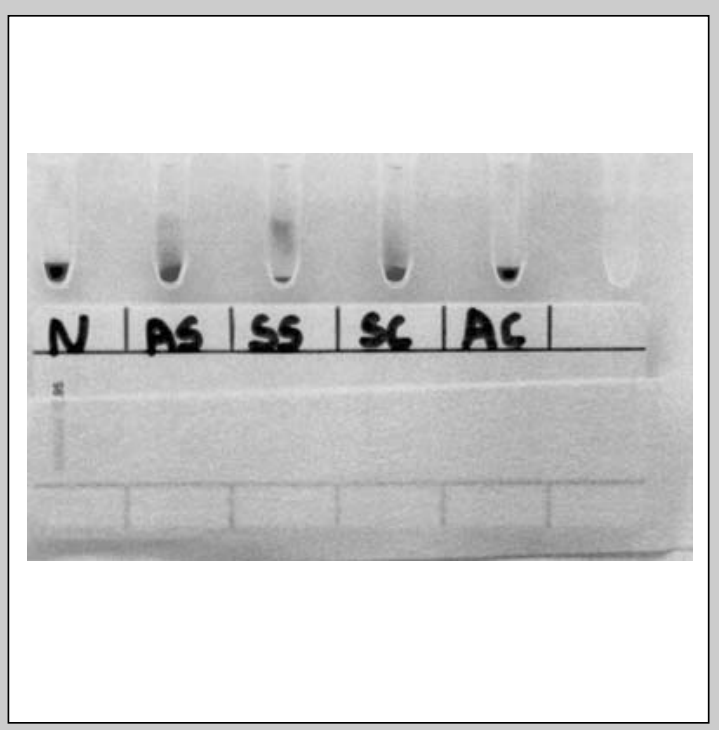

Figura 1. Testes com ID-Card Sickle cell test mostrando amostras $\mathrm{N}$ (normal), AS, SS, AC

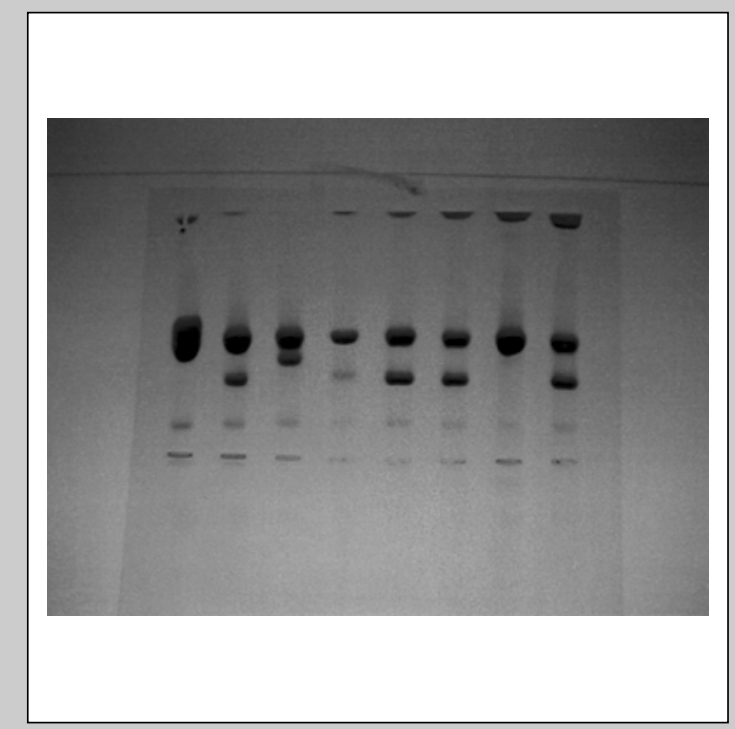

Figura 3. Eletroforese em pH alcalino (8,2), on de se visualizam as hemoglobinas AS nas amostras de número 2, 5, 6 e 8

\section{Discussão}

As doenças falciformes são as alterações genéticas mais comuns em nosso país $(7,18)$. 0 Brasil, país de proporções continentais, caracterizase por significativa mistura racial, em que 0 processo de colonização teve grande influência na dispersão de genes anormais, incluindo

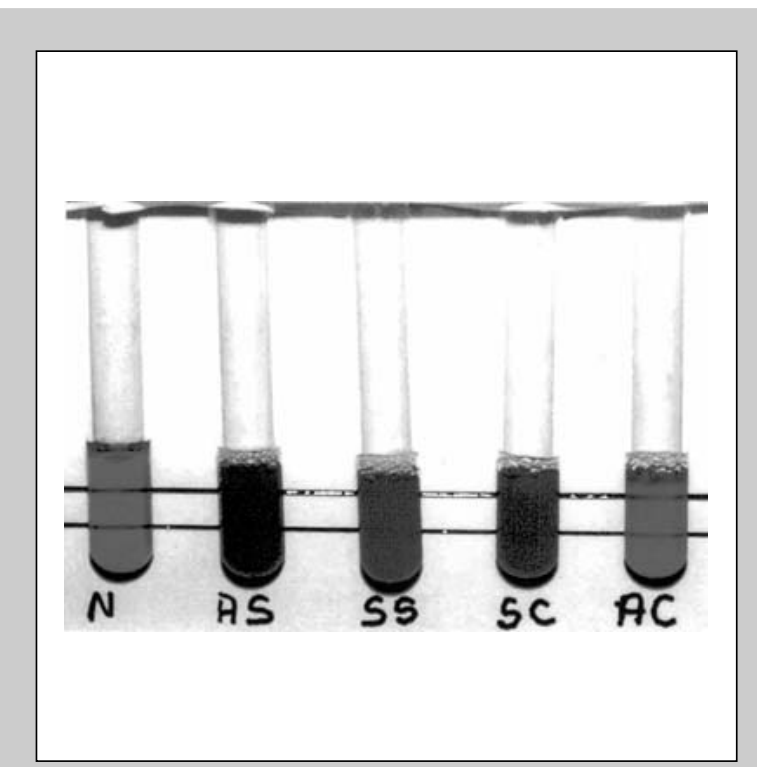

Figura 2. Teste de solubilidade com amostras $\mathrm{N}$ (normal), AS, SS, SC, AC

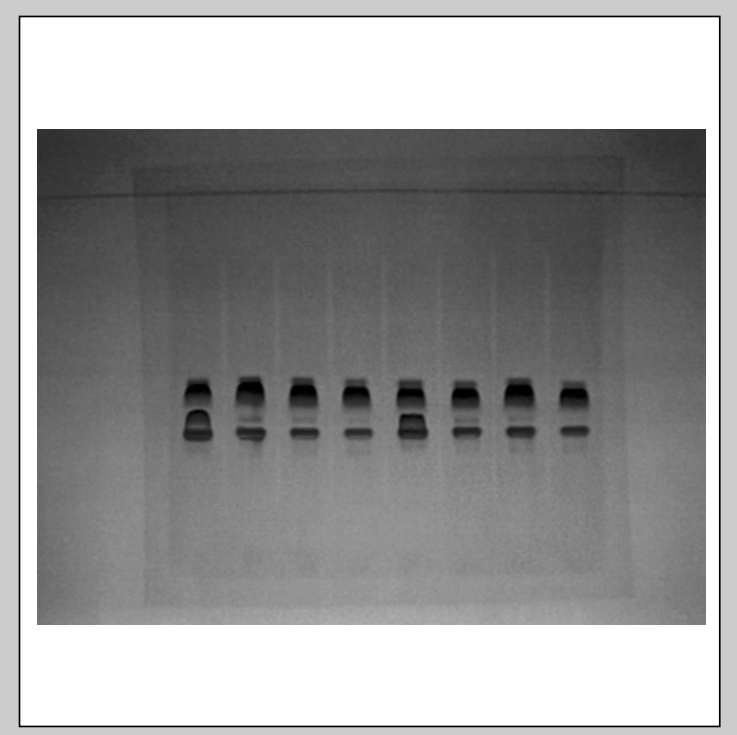

Figura 4. Eletroforese em pH ácido $(6,2)$, com visualização das amostras com hemoglobinas AS confirmadas nas posições 1 e 5

talassemias e falcemias (21). A distribuição das hemoglobinas anormais, provenientes de formas variantes e talassemias, está intimamente relacionada com as etnias que compõem nossa população e análises realizadas em indígenas brasileiros não miscigenados revelaram ausência de hemoglobinas anormais entre diversas tribos de diferentes regiões $(22,23,24,25)$. 
Nos estudos de prevalência de hemoglobinopatias realizado em diferentes regiões do Brasil $(9,16,26,27)$ a Hb S e Hb C, ambas de origem africana, mostram a intensa participação do negro na composição populacional brasileira $(21,13,14,25)$.

De acordo com a NTMS (portaria 1376 de 19/11/1993), é recomendável a detecção de Hb S devido à sua alta prevalência (25 a $45 \%$ ) na população brasileira. Diante deste fato, a chance de encontrarmos um receptor com traço falciforme é grande, o que diminuiria a eficácia da transfusão. Por outro lado, o número de células anormais faria com que, mesmo receptores com $\mathrm{Hb} A A$, tivessem uma transfusão ineficiente, não cumprindo assim o seu papel, e obteríamos uma transfusão com "vida mais curta", uma vez que a concentração de $\mathrm{Hb}$ A seria menor. No paciente portador de $\mathrm{Hb} \mathrm{S}$, se transfundirmos sangue com $\mathrm{Hb}$ AS, estaremos aumentando a concentração de $\mathrm{Hb} \mathrm{S}$ em torno de $90 \%$, uma vez que a quantidade de $S$ no portador AS é de 25 a $45 \%$, portanto, diminuindo a sua oxigenação, podendo aumentar o risco de hemólise $(28,33,34,35)$.

Mesmo em pacientes normais ( $A A)$, debilitados e com quadro de hipóxia, o sangue transfundido com Hb AS poderá provocar uma hemólise intra vascular. Mollison e cols, 1997 (28), não utilizam sangue com $\mathrm{Hb}$ AS para transfusão em RN e exsanguíneo transfusão em pacientes SS ou em pacientes submetidos a cirurgia, devido à oxigenação ineficiente que tal sangue provocaria. Já, Ould Amar e cols, 1996 (29), reforçam esta tese proibindo a transfusão de sangue AS em RN. Bodensteiner, 1994 (30), relatou e Ould Amar e cols, 1997 (31) corroboraram que, sangue AS, quando submetido a filtro de leucócito, tem uma velocidade de filtração menor que o sangue $A A$ e a eficiência na retenção de leucócitos é muito menor que no sangue sabidamente $A A$, podendo ainda ocorrer obstrução nestes filtros $(28,29,30,31)$.

Devido à alta prevalência de hemoglobina S em nosso país, esta triagem permite esclarecimento e "aconselhamento" para portadores assintomáticos, não só para orientação de reprodução, mas também como orientação, uma vez que várias profissões ou esportes têm fator de risco aumentando para Hb S, como vôo em avião não pressurizado, pára-quedismo, esforço físico em grandes altitudes, ou mesmo em altitude normal, ou após excesso de esforço físico. Há relato de morte súbita, após anestesia, quando em transfusão por sangue com Hb S $(32,33,35,17,39)$.

Por ser uma alteração de cadeia de globina, com mudança de carga elétrica, a hemoglobina $\mathrm{S}$ geralmente é triada e diagnosticada por métodos eletroforéticos em que se observa sua migração característica (10, 34, 35). A associação de métodos eletroforéticos em diferentes $\mathrm{pH}$ e/ou testes de solubilidade e ID-Diamed mostra eficiência para o correto diagnóstico, tendo em vista que, para triagem em doadores de sangue faz-se necessário 0 uso de técnicas simples $(8,9,35)$.

Diante da necessidade de adaptarmos as normas de banco de sangue aos custos e necessidades oferecidos pelo governo, no presente trabalho objetivamos a padronização de técnicas de triagem de hemoglobina $\mathrm{S}$ em doadores de sangue, para ser utilizada como modelo nos bancos de sangue. Muitos dos grandes serviços utilizam a eletroforese de hemoglobinas, método que impõe algumas limitações quanto ao uso na rotina de bancos de sangue, principalmente no treinamento de pessoal capacitado para o diagnóstico; por outro lado, o teste de falcização amplamente utilizado em serviços de Hemoterapia, apresenta limitações técnicas, pois casos de falsos positivos e falsos negativos são muito frequentes e de difícil controle, tendo em vista as variáveis a serem testadas, como validade curta do reagente, má vedação das lamínulas e inexperiência na leitura das amostras testadas. Desta forma, tal teste fica inviabilizado para uso em grande escala, devido à margem de erro.

O número médio de doações no Brasil, de acordo com informações do Ministério da Saúde (36), é de 2.500 .000 ao ano. 0 preço por exame para detecção $\mathrm{Hb}$ S pelo método ID Hb S (Diamed) é de $R \$ 1,20$ por doador, o que totaliza $\mathrm{R} \$ 3.000 .000,00$ ao ano. Propomos a utilização do método de solubilidade, igualmente eficiente, ao custo de $R \$ 0,14$ o teste, significando um gasto de $R \$ 350.000,00$ ao ano, ou seja $11,66 \%$ do valor gasto no teste anterior, com uma economia de $\mathrm{R} \$ 2.650 .000,00 /$ ano. Aliado a este importante barateamento do custo, a facilidade na execução do teste e a estabilidade dos reagentes permitem que o mesmo seja utilizado 
em qualquer número de amostra, servindo para grandes e pequenos serviços de hemoterapia.

0 teste de solubilidade tem como princípio reduzir a $\mathrm{Hb} \mathrm{S}$, que é relativamente insolúvel no tampão inorgânico, enquanto outras hemoglobinas são solúveis. A molécula de hemoglobina é um tetraedro trançado composto por duas cadeias alfa e duas cadeias beta, com assimetria de "espelho" com referência ao eixo central da molécula (37). Quando há desoxigenação, ocorre o deslocamento lateral das cadeias beta. Na oxigenação o movimento é contrário, voltando as cadeias beta para junto do eixo. A lise dos eritrócitos, quando na mistura de ditionito de sódio no teste de solubilidade, libera hemoglobina desoxigenada e a cadeia beta de cada molécula se desloca lateralmente, causando "opacidade" na leitura do teste.

Devido à grande quantidade de $\mathrm{Hb} F$ no período neonatal, que funciona como "efeito diluidor", testes como o de falcização, que utilizam metabisulfito de sódio, e de solubilidade com ditionito de sódio freqüentemente resultam em falsos negativos.

0 teste de solubilidade apresenta boa sensibilidade para a triagem de $\mathrm{Hb} \mathrm{S}$ em outras faixas etárias, com eficácia de 99,8\% na identificação desta hemoglobina, oferecendo ainda custo mais baixo do que a eletroforese bem como fácil execução $(8,38,39,40,41,42,43)$.

0 teste de solubilidade baseia-se no fato de que, sob baixas concentrações de oxigênio, a $\mathrm{Hb}$ S torna-se 100 vezes menos solúvel que sua forma oxigenada $(8,44,45,46,47,48)$.

Existem algumas condições onde pode haver falso positivo e falso negativo no teste de solubilidade, tais como:

I - Condições que causam teste falso positivo: 1 - Policitemia, 2 - Excesso de sangue na reação, 3 - Mieloma múltiplo, 4 - Hb Bart's, Hb C Harlem, 5 - Transfusão recente, 6 Insuficiência renal crônica.

II - Condições que causam teste falso

negativo: 1- Q uantidade inadequada de sangue $\mathrm{Hb}<7 \mathrm{~g} \%$, 2- Deterioração e inatividade dos reagentes, 3 - Dificuldade na leitura, 4 - Hb S em pequena quantidade (ao nascimento e após transfusão).

Nos casos falsos positivos, sugere-se a repetição dos mesmos com hemáceas lavadas, visto que a proteína plasmática seria retirada e com isso o "fator positivador" da reação também. Porém, o fato da interferência da proteína não é explicado (49). Del Guidice, em 1979 (50), também relata $100 \%$ de compatibilidade entre o teste de solubilidade e eletroforese de hemoglobina em portadores de $\mathrm{Hb} \mathrm{S}$, com apenas um caso positivo por portadores de mieloma múltiplo, que é sabidamente uma patologia com proteína alterada.

Das condições acima citadas, tanto nos falsos positivos quanto nos falsos negativos, a maioria das situações são condições que contra-indicam a doação, ficando apenas uns poucos fatores que, com a padronização da técnica podem ser evitados, como a quantidade de reagente, prazo de validade e concentração das amostras.

Do total de 5.416 doadores analisados, 50 $(0,92 \%)$ apresentaram $\mathrm{Hb}$ AS, e as diferenças entre sexo não apresentam significado estatístico, uma vez que a herança desta alteração genética é autossômica recessiva (10). Observamos em nosso estudo maior presença de doadores do sexo feminino em coletas externas, quando comparada a coletas realizadas em nosso Núcleo, provavelmente pelo fato de a coleta ser programada e estas mulheres ajustarem seus horários com esta atividade.

Ainda com relação ao total analisado, observamos uma alta freqüência de brancos, quando comparados com negros e mulatos, 0 que pode ser explicado pela característica de colonização da região, que foi de italianos, com as posteriores miscigenações. Entre os 50 (0,92 \%) indivíduos com $\mathrm{Hb}$ AS encontrados, observamos que a freqüência desta hemoglobina entre os $22(0,40 \%)$ brancos e 20 $(0,36 \%)$ mulatos foi muito próxima, também explicada pelo alto grau de miscigenação de nossa população. Quando separamos o total analisado em duas regiões, Fernandópolis e Araçatuba, observamos 23 (0,57\%) doadores com Hb AS em Fernandópolis e 27 (1,90\%) em Araçatuba, sendo que existe um percentual maior de negros e mulatos na região de Araçatuba do que na região de Fernandópolis, devido, principalmente, ao grande fluxo de italianos para esta região na década de 1940, onde o café era a cultura predominante e as famílias italianas, geralmente com prole 
numerosa, vinham realizar o trabalho agrícola, aqui se fixando e deixando seus descendentes.

As análises laboratoriais aplicadas neste estudo para detectar Hb S mostraram $100 \%$ de compatibilidade e foram confirmadas por procedimentos eletroforéticos específicos, mostrando ser o teste de solubilidade viável para aplicação em rotina na hemoterapia, quando o objetivo for detectar $\mathrm{Hb} \mathrm{S}$, a um custo pequeno e sem grandes investimentos em treinamento de pessoal, por ser de simples realização.

Apesar das $\mathrm{Hb} \mathrm{S}$ e $\mathrm{D}$ apresentarem 0 mesmo padrão de migração eletroforético em pH alcalino, não corremos o risco de encontrar portadores desta patologia entre os portadores triados, porque a $\mathrm{Hb} \mathrm{D}$ comporta-se como a $\mathrm{Hb}$ A em testes de solubilidade $(8,35)$.

Dada a baixa freqüência de $\mathrm{Hb} \mathrm{S}$ em nossa região, compatibilizamos um grupo de 213 negros e descendentes, onde a freqüência é sabidamente mais elevada, e obtivemos um resultado de $100 \%$ de compatibilidade, o que nos deu a segurança no uso do teste de solubilidade.

A utilização da eletroforese de hemoglobina para uso de rotina em banco de sangue é dificultada, não só pelo custo da análise, mas também pelo tempo de realização do exame e treinamento de pessoal. Devido à dificuldade técnica e econômica da eletroforese de hemoglobina e testes ID-Diamed, sugerimos como método de escolha para triar a $\mathrm{Hb} \mathrm{S}$ em doadores de sangue, a técnica de solubilidade, que se adequa pela praticidade, economia, durabilidade dos reagentes, precisão nos resultados e se aplica com segurança às grandes e pequenas rotinas. Os casos triados deverão passar por eletroforese de hemoglobina para que seja confirmado seu genótipo e assim realizar a orientação aos seus portadores, que geralmente desconhecem o fato de serem portadores de uma hemoglobina anormal, e garantir assim a qualidade da transfusão, quanto ao risco de eficiência e efeitos indesejáveis da mesma.

\section{Conclusão}

A realização dessa pesquisa hematológica deveu-se à recomendação para a detecção de hemoglobinas anormais em doadores de sangue, regulamentada pela portaria 1376 do Ministério da Saúde, aliada à freqüência de $\mathrm{Hb} \mathrm{S}$ na população e aos valores normais da hemoglobina quando da pré-triagem dos doadores, bem como às contra-indicações em se transfundir sangue com $\mathrm{Hb} \mathrm{S}$.

Nosso estudo pautou-se nos testes de compatibilidade de técnicas de uso geral em nossos serviços de hemoterapia, visando a garantir a qualidade dos mesmos. Foram compatibilizadas as técnicas ID - Hb S (Diamed) e teste de solubilidade em 5416 doadores de sangue, cujos casos positivos foram confirmados pela eletroforese de hemoglobina. A compatibilidade foi de $100 \%$, o que nos levou a concluir que devido à praticidade, segurança, confiabilidade e baixo custo, o teste de solubilidade merece a escolha para utilização em pequenos e grandes serviços.

\section{Hemoglobin Sin blood donors-Comparison of detection methodologies}

Brígida C. A. B. Prudêncio, Dimas T. Covas, Claudia R. Bonini-Domingos

\section{Abstract}

According to the governmental act number 1376 from November 19, 1993, concerning technical norms for collecting, processing, and transfusing blood, parts and substracts, detection of unusual $\mathrm{Hb}$ blood donors must be performed. In Brazil, the high prevalence of $\mathrm{Hb} \mathrm{S}$, clearly related to regional differences as a consequence of miscegenation process has been studied not only in $\mathrm{Hb}$ SS patien ts with sickle cell disease but also in $\mathrm{Hb} \mathrm{S}$ carriers (Hb AS).

In this study our objective is to identify $\mathrm{HbAS}$ using technical comparisons for selection such as ID HbS (Diamed) and solubility test, and subsequently positive cases are confirmed with electrophoresis pH alkaline and acid.

From 5.416 donors analyzed using the selection tests ID Hb S Diamed and solubility, 50 (0.92\%) showed Hb S which was confirmed in $100 \%$ of the cases showing compatibility of the techniques involved. This makes the solubility test the best choice in blood banks not only because of its efficiency but also its practicability and low cost. Rev.bras.hematol.hemoter., 2000, 22(2): 99-109

Key Words: blood donors, diagnostic, hemoglobin S 


\section{Referências Bibliográficas}

1. Lee, G. R.; Bithell, T. C.; Foerster J.; Athens, J. W.; Lukens, J. N.; Wintrobe's Clinical Hematology, vol I, 9a ed, Philadelphia,. Lea \& Febiger, 1993.

2. Harmening, D.M. Clinical Hematology and Fundamentals of Hemostasis. 3a ed. Philadelphia, F.A. Davis Company, 1997.

3. Champe, P.C.; Harvey, R.A., Bioquímica Ilustrada. Artes Médicas, 1996.

4. Lehmann, H.; Huntsman R. G. Man's Haemoglobins. Netherland, North Holland Publishing Company, 1974.

5. Beutler, E.; Lichtman, M. A.; Coller B.S.; Kipps, T.J. Williams Hematology. ${ }^{\mathrm{a}}$ ed. New York, International Edition, 1995.

6. Marinho, H.M Hematologia. São Paulo, Sarvier, 1984.

7. Naoum, P.C. Hemoglobinopatias e Talassemias. São Paulo Editora Sarvier, 1997.

8. Naoum, P.C.; Diagnóstico das Hemoglobinopatias. Editora Sarvier, São Paulo, 1987.

9. Domingos, C.R.B., Prevenção das Hemoglolinopatias no Brasil. São José do Rio Preto, 1993. Tese (doutorado) - Instituto de Biociências Letras e Ciências ExatasUniversidade Estadual do Estado de São Paulo.

10.Honig, G. R.;Adams III, J.G. Human Hemoglobin Genetics. New York, Springer Verlag , 1986.

11.IHIC - International Hemoglobin Information Center - Alphabetical Hemoglobin Variant List. Hemoglobin, v.20, n.3, 313-335, 1996.

12.Brasil. Ministério da Saúde. Gabinete do Ministro. Portaria n. 1.376 de 19 de novembro de 1993. Aprova as altera ções da Portaria n. 0 721/GM, de 09/08/89, que aprova as Normas Técnicas para coleta, processamento e transfusão de sangue, componentes e derivados, e dá outras providências. Brasília, Diário Oficial da União, p. 18404, 2 de dezembro de 1993.

13. Alvares Filho, F; Naoum, P. C.; Moreira, H.W.; Angulo, I.L. Variabilidade polimórfica das hemoglobinas humanas anormais em indivíduos das cidades de Barretos e Colina, SP - Brasil. Revista Brasileira de Patologia Clin., v.24, nํ2, p.32, 1988.
14. Alvares Filho, F. 0 gene beta $S$ (hemoglobina S) no Brasil. Distribuição geográfica, etária e racial. São José do Rio Preto, 1990. Tese (doutorado) - Instituto de Biociências, Letras e Ciências Exatas - Universidade Estadual do Estado de S. Paulo.

15.Alvares Filho, F.; Naoum, P.C.; Moreira, H.W.; Cruz, R.; Manzato, A. J.; Domingos, C.R.B.; Distribución Geográfica etária y racial de la hemoglobina S en Brasil; Sangre, v. 40, n.2, p. 97-102, 1995.

16. Hutz, M.H.; Salzano, F.M. Sickle cell anemia in Rio de Janeiro, Brazil: demographic, clinical and laboratorial data. Brazilian Journal of Medical Biological Research, v.16, p.219-226, 1983.

17. Naoum, P.C.; Domingos, C.R.B. Doença falciforme no Brasil. Origem, genótipos, haplótipos e distribuição geográfica. Jornal Brasileiro de Patologia, v.33, n.3, p. 145-153, 1997.

18. Ramalho; A.S.; Hemoglobina Sem doadores de sangue brasileiros, Rev. Associação Médica Brasileira, v. 22, n.12, p. 467-468, dez. 1976.

19. Marengo - Rowe, A.J. Rapid electrophoresis and quantitation of hemoglobin on cellulose acetate. Journal Clinical Pathology, 18:790-792, 1965.

20. Vella, F. Acid agar gel eletrophoresis of human hemoglobin. American Journal Clinic Pathology, 49; 440, 1968.

21. Naoum, P.C. Anemias imigrantes. A origem dasanemias hereditáriasno Brasil. Ciência Hoje, v.3, n.14, p.59-64, 1984.

22. Zago, M.A.; Costa, F.F.; Ismael, S.J.; Bottura, C.; Enfermedades drepanocíticas en una población brasilena; Sangre, v.28, n.2, p.191-197, 1983.

23. Zago, M.A.; Costa F.F.; Tone, L.G.; Bottura, C.; Hereditary Hemoglobin Disorders in a Brasilian Population; Hum Herd. v.33, p.125-129, 1983.

24. Zago, M. A. Origem e heterogen eidade da anemia falciforme, Boletim, v. XV n.162, p.3-8, 1993.

25. Guerreiro, I.F.; Figueiredo, M.S.; Santos, S.E.B.; Zago, M.A. b Globin gene cluster haplotypes in Yanomama Indians from the Amazon Region of Brazil. Hum Genet, v. 89, p.629-631, 1992. 
26. Salzano, F.M. Hemoglobin variants in Brazil. Winter, W.P. edr CRC press, Boca Raton, Florida, p.117-130, 1986.

27. Lima, J.C.S. Interação de Anemia falciforme e a Talassemia: Aspectos moleculares, clínicos, hematológicos e bioquímicos - Um estudo na população brasileira. Rio de Janeiro, 1997. Tese (Doutorado) - Instituto de Biologia, Universidade Federal do Rio de Janeiro.

28. Mollison; P.L.; Engelfriet, C.P.; Contreras, M. Blood transfusion in clinical medicine. 10.ed. London, Blackwell Science, 1997.

29. Ould Amar, A. K.; Kérob-Bauchet, B.; Robert, P.; Leconte, C.; Maier, H.; Bera, O.; Plumelle, Y.; Hyronimus, J.C.; Césaire, R. Assessment of qualitative functional parameters of stored red blood cells from don ors with sickle cell trait (AS) or with heterozygote(AC) status. Transfusion Clinique et Biologique, v.4, p. 225-233, 1996.

30. Bodensteiner, D. White cell reduction in blood from donors with sickle cell trait. Transfusion, v.34, n.1, p. 84, 1994.

31. Ould Amar, A.K.; Cesaire, R.; KerobBouchet, B.; Robert, P.; Maier, H.; Bucher, B. Altered filterability of fresh sickle cell trait don or blood. Vox Sanguinis, v. 73, p. 55-56, 1997.

32. Francis, C.K.; Bleakley, D.W.; The Risk of Sudden Death in Sickle Cell Trait: Noninvasive Assessment of Cardiac Respouse to Exercise. Catheterization and Cardiovascular Diagnosis, v.6, p.73-80, 1980.

33. Hall, J.R.; Clemency, M.V.; Clarke, G.; Steele, M.A.; Farhi, D.; Silva, V.A. Effects of blood salvage and cell saver processing on sickle cell trait blood. Anesthesiology, v.85, n.3A, 1996.

34. Higgs, D.R.; Weatherall, D.J. The Ha emoglobin opathies;

Clinical

Hematology, v.6, n.1, 1993.

35. Embury, S.H.; Hebbel, R.P.; Mohandas, N.; Steinberg, M.H. Sickle cell disease basic principles and clinical pratice. New York, Raven Press, 1994.

36. Souza, H.M. participação do governo e da sociedade na organização da Hemorrede no Brasil. Série de Monografias da Escola Brasileira de Hematologia. v.5, p.1-6, 1998.

37. Murayama, M; Nalbandian, R.M.; Sickle cell hemoglobin: Molecule to man. Boston, Mass, Litte Brown and Co, 1973.

38. Huntsman, R. G.; Barclay, G. P. T.; Canning, D. M.; Yawson, G. I.; A rapid whole blood solubility test to differentiate the sickle-cell trait from sickle-cell anaemia; Journal Clinic Pathology, 23, 781-783, 1970.

39. Serjeant, B. E.; Serjeant, G. R.; A whole blood solubility and centrifugation test of sickle cell hemoglobin: a clinical trial, American Journal of Clinical Pathology, v.58, p. 11-13, 1972.

40. Asakura, T.; Segal, M.E.; Friedman, S.; Schuvartz, E. A rapid test for sickle hemoglobin. JAMA, v. 233, n. 2, p. 156157, 1975.

41. Warren, B.; Crasby, G.; Evans, G.L. A new rapid differentiating solubulity test for hemoglobin S. American Journal of Medical Technology, v.41, n.9, p. 317321, 1975.

42. Zago, M.A.; Costa, F.F. Botura C.; Teste de solubilidade quantitativo modificado em hemolisados normais e em variantes da hemoglobina; Revista Paulista Medicina, v.100, n.3; p. 15-17, 1982.

43.Liao, D.; Llano, J. J. M.; Himanen, J. P.; Manning, J. M.; Ferrone, F. A.; Solubility of Sickle Hemoglobin Measured by a Kinetic Micromethod; Biophysical Journal; v. 70, p. 2442-2447, 1996.

44.Pereira, J.M.; Meneghine, T.; Vieira, A.A.; Pessoa, A.L.C.; Santos, V.C.; Callado, A.N.A.; "Sickledex" um rápido teste de solubilidade para detecção de hemoglobina; Revista Brasileira de Análises Clínicas, v. 3, n.3 setembro/ dezembro 1971.

45.Raper, A. B.; Solubility Test for Hb S, British

Medical Journal. v.1, p.460, 1971.

46.Schimidt, R. M. Laboratory Diagnosis of Hemoglobinophathies: JAMA, v 224, n.9, p.1276-1280, 1973.

47.Louderback, A.L.; Youhne, Y.; Fontana, A.; 
Natland, M. Clinical Evaluation of a Rapid Screening Test for Sickle Cell Trait (S) and SickleCell Anemia (SS). Clinical Chemistry, v. 20, n.7, p. 761-764, 1974.

48. Steinberg, M. H.; Adams III, J. G. Laboratory diagnosis of sickling hemoglobinopathies; Southern Medical Journal, v. 71, p. 413-416; 1978.

49. Lilleyman, I.S.; Bills, T.; Guyer, H.J. False positive results with a rapid solubilits test for hemoglobin S. Journal Clinical Pathology, v.85, n.5, p.458-460, 1972.

50. Del Guidice, R.E.; Doaring, R.M.; Teran, A. Evaluation of sicklequick a differential solubility test for hemoglobin S. American Journal of Medical Technology, v.45, n.4, p. 287-289, 1979.

Recebido: $10 / 04 / 00$

Aceito: $20 / 06 / 00$ 